\title{
Self-Administered Heroin and Cocaine Combinations in the Rat: Additive Reinforcing Effects - Supra-Additive Effects on Nucleus Accumbens Extracellular Dopamine
}

\author{
James E Smith*,', Conchita Co', Michael D Coller', Scott E Hemby' and Thomas J Martin' \\ 'Center for the Neurobiological Investigation of Drug Abuse, Department of Physiology and Pharmacology, Wake Forest University School of \\ Medicine, Wake Forest University, Winston-Salem, NC, USA
}

\begin{abstract}
The concurrent use of cocaine and opiate combinations (speedball) has increased since the 1970s and now represents a growing subset of intravenous drug abusers. An isobolographic analysis was applied to the ascending limb of the dose-effect curves for rat selfadministration of cocaine, heroin, and their combination to determine the nature of the interaction. The addition of heroin to cocaine shifted the dose-effect curve for self-administration to the left, and the modulation in reinforcing efficacy of the combination of cocaine and heroin was found to be additive. A second experiment used microdialysis to determine the effects of this drug combination on nucleus accumbens (NAc) extracellular levels of dopamine $\left([D A]_{e}\right)$ in rats self-administering low doses of cocaine, heroin, or cocaine/ heroin combinations. These doses of cocaine and cocaine/heroin combinations significantly increased NAc [DA] $]_{e}$ while heroin alone did not. The ratio of the $\%$ baseline of $[D A]_{e}$ (or the dialysate concentrations of DA) to cocaine in the dialysate was higher during selfadministration of cocaine/heroin combinations than with cocaine alone. These data indicate that although the interaction between cocaine and heroin in maintaining self-administration is additive, a potentiation of NAc dopaminergic neurotransmission is present, suggesting that NAc $[D A]_{e}$ may not be a direct measure of reinforcing efficacy and/or it is not central to the mediation of the selfadministration of this drug combination.

Neuropsychopharmacology (2006) 3 I, 139-150. doi: I 0. I038/sj.npp. I 300786; published online I June 2005
\end{abstract}

Keywords: dopamine; microdialysis; speedball; cocaine; heroin; self-administration

\section{INTRODUCTION}

Data from clinical research indicate that the use of cocaine and opiate combinations represents a growing subset of intravenous drug abusers. One study found that $63 \%$ of intravenous drug users concurrently used cocaine and heroin and/or their combinations within the past 6 months and $58 \%$ within the past 30 days (Schütz et al, 1994). In addition, the incidence of cocaine use in individuals on methadone or LAAM maintenance treatment for opiate abuse is significant (Magura et al, 1998; Craddock et al, 1997). This co-abuse clearly has negative consequences since high levels of cocaine use at intake decreased the likelihood of a positive treatment outcome for opiate addicts (Downey et al, 2000). Laboratory studies of opiate addicts taking high doses of methadone reported larger

\footnotetext{
*Correspondence: Dr JE Smith, Department of Physiology and Pharmacology, Wake Forest University School of Medicine, Wake Forest University Health Sciences, Medical Center Blvd., WinstonSalem, North Carolina, NC 27I57-I083, USA, Tel: + I 336 7I6 8506, Fax: + I 336 716 850।, E-mail: jamsmith@wfubmc.edu

Received 7 July 2004; revised 31 March 2005; accepted 25 April 2005 Online publication: 29 April 2005 at http://www.acnp.org/citations/ NPP0429050403 I7/default.pdf
}

cocaine effects than those receiving lower methadone doses (Foltin et al, 1995; Preston et al, 1996) and greater physiological and subjective effects of cocaine in methadone maintained $v s$ nonmaintained opiate addicts (Foltin et al, 1995) suggesting potential synergism. In contrast, additive or subadditive effects of the combination of cocaine and morphine on both the subjective and cardiovascular effects have been reported in a laboratory study of experienced opiate users (Foltin and Fischman, 1992). To further complicate the issue, clinical research has shown heightened euphoric effects from the drug combination compared with either drug alone (Ellinwood et al, 1976; Wesson and Smith, 1977; Kosten et al, 1986, 1987; Rosen and Kosten, 1991; Tutton and Crayton, 1993; Walsh et al, 1996; Wang et al, 2001).

Research from the animal laboratory is also contradictory. Experiments in non-human primates indicate that the dose-intake relationship for smoked heroin and cocaine combinations was not different from cocaine alone (Mattox et al, 1997). In addition, the dose-intake relationship for intravenous cocaine and heroin combinations was not different from cocaine or heroin alone (Mello et al, 1995). In contrast, $\mu$ and $\delta$-opioid receptor agonists potentiated the reinforcing effects of cocaine in rats responding on a 
progressive ratio schedule of drug availability (Ranaldi and Munn, 1998). However, similar studies in monkeys showed no potentiation (Rowlett and Woolverton, 1997), although an economic-demand function assessment of smoked cocaine, heroin, and the combination showed the demand for heroin alone to be significantly lesser than the demand for the combination, suggesting synergism (Mattox et al, 1997). In addition, a recent self-administration experiment in non-human primates that utilized a dose addition analysis found that cocaine/heroin interactions on drug choice and on response rate measures were subadditive (Negus, 2005).

Dopaminergic activity in the nucleus accumbens (NAc) has been thought to be central to the brain processes that mediate the reinforcing properties of drugs of abuse (Di Chiara and Imperato, 1988; Koob and Bloom, 1988). For example, in vivo microdialysis studies indicate that extracellular levels of dopamine $\left([\mathrm{DA}]_{\mathrm{e}}\right)$ in the NAc are elevated during amphetamine and cocaine self-administration (Ranaldi et al, 1999; Pettit and Justice, 1989). The effects of the self-administration of opiates on these indices are less consistent with both increases (Wise et al, 1995) and no significant effect reported (Hemby et al, 1995, 1999). However, in the latter circumstance where chronic selfadministered heroin was reported to not increase NAc $[D A]_{\mathrm{e}}$ (Hemby et al, 1995, 1999), heroin self-administered in combination with cocaine on the descending limb of the dose-intake relationship significantly potentiated the effects of cocaine on NAc [DA $]_{e}$ (Hemby et al, 1999). This is in agreement with data showing acute response-independent heroin (Zernig et al, 1997) and buprenorphine (Brown et al, 1991) to enhance the effects of cocaine on NAc $[D A]_{e}$. The purpose of the present experiments was: (1) to use an isobolographic analysis of rat self-administration of cocaine, heroin, and the combination of cocaine with heroin to determine the nature of the interaction between these two drugs, and (2) to use microdialysis to determine the effects of this drug combination on NAc $[D A]_{e}$ in rats selfadministering low doses of cocaine, heroin, or cocaine/ heroin combinations.

\section{MATERIALS AND METHODS}

\section{Animals}

In all, 23 adult male Fischer F-344 90-150-day-old rats (Harlan, Indianapolis, IN) were used (six for the isobolographic analysis and 17 for the microdialysis experiment). The rats were housed in a temperature-controlled environment on a reversed 12-h light-dark cycle (lights on 17000500) with food and water available ad libitum except during experimental sessions. Experiments were performed in accordance with the National Institutes of Health Guide for the Care and Use of Laboratory Animals (NIH Publication No. 80-23) revised in 1996.

\section{Surgical Techniques}

Intravenous catheters. Rats were anesthetized with pentobarbital $(50 \mathrm{mg} / \mathrm{kg}$, i.p. - Abbott Laboratories, North Chicago, IL) after pretreatment with atropine methyl nitrate $(10 \mathrm{mg} / \mathrm{kg}$, i.p. - Sigma, St Louis, MO) and penicillin G procaine (75000 U, i.m. - Wyeth Laboratories, Philadelphia, PA) and implanted with venous catheters placed in the right jugular vein using previously described methods (Weeks, 1962, 1972; Pickens and Dougherty, 1972). The catheter (a small piece of polyvinyl-chloride tubing) was inserted into the right posterior facial vein, guided into the right jugular vein until it terminated just outside the right atrium and anchored to muscle in the area of the vein. The other end of the catheter continued subcutaneously to the back where it exited between the scapulae through a polyethylene shoulder harness. The harness provided a point of attachment for the catheter to a needle-tubing leash that passed out the top of the animal chamber. A leak proof swivel (Brown et al, 1976) was used to attach the leash to the tubing leading to the infusion pump so that the animals had almost complete freedom of movement. The rats were allowed to recover for 7 days before the initiation of experimental procedures with programmed infusions $(0.2 \mathrm{ml}$ delivered over $6.2 \mathrm{~s})$ of heparinized saline (1.7 U/ $\mathrm{ml}$ ) administered at hourly intervals in the home cage to maintain functional catheters. Patency of catheters was evaluated at regular intervals by delivering an intravenous infusion of methohexital ( $10 \mathrm{mg} / \mathrm{kg}$ - Eli Lilly, Indianapolis, IN) and determining the latency for loss of stability or consciousness which occurs within 1-2 s.

Intracranial guide cannula for microdialysis probes. In all, 17 rats were implanted with microdialysis guide cannula CMA11 (CMA/Microdialysis, North Chelmsford, MA) to terminate at the dorsal surface of the NAc $(9.4 \mathrm{~mm}$ from lambda, $\pm 1.7 \mathrm{~mm}$ lateral from the midline, and $5.0 \mathrm{~mm}$ ventral from the dura (König and Klippel, 1967)) using a stereotaxic (Stoelting, Wood Dale, IL). The guide cannulas were secured to the skull with stainless steel screws and dental acrylic cement and obturators (28 g) inserted to prevent blockage.

\section{Drugs}

Cocaine hydrochloride and heroin hydrochloride were obtained from the Drug Supply Program of the National Institute on Drug Abuse. Pentobarbital was purchased from Abbott Laboratories (North Chicago, IL), sodium heparin from Elkin-Sinn (Cherry Hill, NJ) and methyl atropine nitrate from Sigma Chemical Co. (St Louis, MO).

\section{Behavioral Procedures}

Drug self-administration. Rats were trained to intravenously self-administer cocaine, heroin, or cocaine/heroin combinations initially under a fixed ratio 1 (FR1) schedule of reinforcement, where one response on the lever was sufficient to deliver a drug infusion during daily sessions using a within-session dose-intake procedure (Martin et al, 1996). This procedure involved sessions that consisted of three 60-min trials where three different doses of the drug were made available for each of the three 60-min trials. A priming infusion of the dose that was available was given at the beginning of each of the three trials. The trials were separated by either 10- (microdialysis experiment) or 20(isobolographic experiment) $\mathrm{min}$ time out (TO). The response requirement was raised to a final ratio of 2 . 
Experimental chambers contained a house light, a stimulus light, response lever, and a tone source. The operant chambers were housed in sound- and light-attenuating cubicles and daily self-administration sessions were conducted 5 days/week. Each drug infusion was paired with a 20 -s tone and light stimulus and the response lever was retracted during the TO periods and at the end of the session.

Isobolographic evaluation of the dose-effect curves for cocaine, heroin, and cocaine/heroin combinations. An evaluation of the interactions between self-administered cocaine and heroin and their combination was accomplished using a previously reported isobolographic procedure (Tallarida et al, 1997). Isobolographic analysis is a method that examines interactions between two drugs that produce monotonic dose-dependent effects and have similar maximal effects. However, the self-administration of cocaine and heroin have different maximal effects and both dose-intake curves are bitonic functions that have inverted U-shapes. For these reasons a single effect level was chosen that was achieved by both drugs for the analysis (15 infusions). Six male, Fischer 344 rats were trained to selfadminister infusions of cocaine in combination with heroin in 4 -h sessions using a within-session dosing procedure with exposure to three doses for $60 \mathrm{~min}$ each as described above for 5 days/week. The doses used for training were $166.5 \mu \mathrm{g} /$ infusion of cocaine in combination with $4.5 \mu \mathrm{g} /$ infusion of heroin, $333 \mu \mathrm{g} /$ infusion of cocaine in combination with $9 \mu \mathrm{g} /$ infusion of heroin, and $666 \mu \mathrm{g} /$ infusion of cocaine in combination with $18 \mu \mathrm{g} /$ infusion of heroin. These doses were chosen because $333 \mu \mathrm{g} /$ infusion of cocaine and $9 \mu \mathrm{g} /$ infusion of heroin maintain similar rates of selfadministration (Martin et al, 1998). The dose was altered by varying the time of operation of the infusion pump and an increasing dose order of presentation was used. The initial response requirement was an FR1, which was raised to 10 over several sessions. When stable responding was obtained at FR10, saline and different cocaine/heroin dose combinations were substituted for the training doses on Tuesdays and Fridays if the behavior on the preceding sessions did not vary by more than $10 \%$ from the overall mean. The dose range of cocaine/heroin was sequentially lowered to $41.6 / 1.1,83.3 / 2.3$, and $166.5 / 4.5 \mu \mathrm{g} /$ infusion, then to $10.4 / 0.3,20.8 / 0.6$, and $41.6 / 1.1 \mu \mathrm{g} /$ infusion, and finally to $5.2 / 0.1,10.4 / 0.3$, and $20.8 / 0.6 \mu \mathrm{g} /$ infusion to generate the remaining portion of the descending and ascending limbs of the dose-effect curve for the combination.

After the cocaine/heroin combination dose-effect curve was obtained, the same doses of cocaine and heroin that were used in the combinations were systematically substituted alone for the training doses of the combination. The rats were maintained at the training doses of each drug or combination and various doses for each drug were substituted for the training doses on Tuesdays or Thursdays, if the behavior on the preceding sessions did not vary by more than $10 \%$ from the overall mean. The animals were exposed to all dose ranges of cocaine, heroin, and speedball with a maximum of two alternate dose ranges per week, with saline extinction evaluated a minimum of twice. The dose range within a session was chosen such that there was one overlapping dose with previous sessions and the data from these overlapping doses were averaged together. In this manner, values for self-administered drug intake were obtained at various doses until both the ascending and descending limbs of the dose-intake relationship were determined for cocaine, heroin, and the cocaine/heroin combinations for each of the six rats.

Self-administration of dose of cocaine, heroin, and cocaine/heroin combinations on the ascending limb of the dose-intake relationship for microdialysis experiments. In all, 17 rats were trained to intravenously selfadminister cocaine $(666,333$, and $166.5 \mu \mathrm{g}$ /infusion; $N=5)$, heroin $(18,9$, and $4.5 \mu \mathrm{g} /$ infusion; $N=6)$, or cocaine/heroin combinations (cocaine/heroin -666/18, 333/9, and 166.5/ $4.5 \mu \mathrm{g}$ /infusion; $N=6$ ) using an FR2 schedule and a withinsession dose-intake procedure as outlined above. Selfadministration sessions were $3 \frac{1}{2} \mathrm{~h}$ in duration 5 days/week with $60 \mathrm{~min}$ access to each dose and a descending order of drug presentation with a 10 -min TO between doses. When stable patterns of self-administration were obtained (the mean number of infusions delivered for each dose of cocaine did not vary by more than $10 \%$ of the mean), the doses of the drugs were decreased by $50 \%$ sequentially over the next 10 sessions until a range of doses was found for which the rats would only consistently self-administer the highest of the three available doses of cocaine (166.5, 83.3, and $41.6 \mu \mathrm{g} /$ infusion; heroin $-4.5,2.3$, and $1.1 \mu \mathrm{g} /$ infusion; cocaine/heroin - 166.5/4.5, 83.3/2.3, and $41.6 / 1.1 \mu \mathrm{g} / \mathrm{infu}-$ sion).

\section{Microdialysis}

When stable patterns of FR2 self-administration were obtained at these low doses, the microdialysis session was initiated. Microdialysis probes were inserted through the previously implanted guide cannula approximately $18 \mathrm{~h}$ prior to the self-administration session during which microdialysis was to occur. The inlet tubing to the microdialysis probe was connected to a syringe containing artificial cerebrospinal fluid and one channel of a dual channel fluid swivel (Instech Laboratories, Plymouth Meeting, PA), while the other channel was used for intravenous cocaine infusions. Artificial cerebrospinal fluid (aCSF; $145 \mathrm{mM} \mathrm{NaCl}, 1.2 \mathrm{mM} \mathrm{CaCl}, 2.8 \mathrm{mM} \mathrm{KCl}, 1.2 \mathrm{mM} \mathrm{MgCl}_{2}$, $5.4 \mathrm{mM}$ D-glucose, and $1.25 \mathrm{mM} \mathrm{NaH} \mathrm{PO}_{4}$ at a $\mathrm{pH}$ of 7.2) was perfused at a rate of $0.5 \mu \mathrm{l} / \mathrm{min}$.

Microdialysis samples were collected into microcentrifuge tubes from the free end of the outlet tubing at 10-min intervals, 30-min pre-session, during the 210-min session, and 60 -min post-session, and the samples immediately frozen on dry ice and stored at $-70^{\circ} \mathrm{C}$ until analysis.

\section{Analysis of DA in Microdialysates by HPLC}

DA was measured in a $1.0 \mu \mathrm{l}$ aliquot of each dialysate using high-pressure liquid chromatography with electrochemical detection (HPLC-EC) consisting of a syringe pump (model LC-260D; ISCO, Lincoln, NE) with an air-actuated injection valve (model ACI4UW; Valco) and a $1.0 \mu \mathrm{l}$ sample loop, a microbore column (Spherisorb, ODS2, $5.0 \mu \mathrm{m}, 0.5 \mathrm{~mm}$ i.d. $\times 100 \mathrm{~mm}$ ), a dual glassy carbon working electrode 
(model PM; EG\&G Princeton Applied Research, Princeton, $\mathrm{NJ}$ ), a reference electrode (RE-1; Bioanalytical Systems Inc., W. Lafayette, IN), and an EC detector (model 400; EG\&G Princeton Applied Research), with the applied potential set at $+700 \mathrm{mV}$ as referenced to $\mathrm{Ag} / \mathrm{AgC}$. The mobile phase consisted of $20 \mathrm{mM}$ citric acid, $46 \mathrm{mM} \mathrm{NaH} \mathrm{PO}_{4}, 0.25 \mathrm{mM}$ EDTA, $0.7 \mathrm{mM}$ 1-decanesulfonic acid, $10 \mathrm{mM}$ triethylamine, and 21\% methanol (v/v), pH 5.4 (Hemby et al, 1997, 1999), and the flow rate of $15 \mu \mathrm{l} / \mathrm{min}$ resulted in a retention time of $5 \mathrm{~min}$ for DA. DA was quantified by comparing samples with standards of known concentration and the limit of detection was $0.5 \mathrm{fmol}$, which corresponded to a concentration of $0.5 \mathrm{nM}$.

\section{Analysis of Cocaine in Microdialysates by HPLC}

Cocaine was measured in a $0.5 \mu \mathrm{l}$ aliquot of each dialysate sample using HPLC and UV detection. The HPLC consisted of an SSI pump (model 222D; Scientific Systems, Inc., State College, PA), a Rheodyne injection valve (model 7520) with a $0.5 \mu \mathrm{l}$ sample loop, a Spherisorb microbore column $\left(0.5 \times 100 \mathrm{~mm}, 3 \mu \mathrm{m} \mathrm{C}_{18}\right)$, and an LDC analytical variable wavelength detector (model 3200). The concentration of cocaine in the microdialysates was measured using UV absorbance at a wavelength of $235 \mathrm{~nm}$. The mobile phase consisted of $50 \mathrm{mM} \mathrm{NaH}_{2} \mathrm{PO}_{4}, 10 \mathrm{mM}$ triethylamine, $0.1 \mathrm{mM}$ EDTA, 22\% acetonitrile, and 15\% methanol, with $\mathrm{pH}$ adjusted to 5.6 and flow rate of $15 \mu \mathrm{l} / \mathrm{min}$, that resulted in a retention time of $8 \mathrm{~min}$ (Hemby et al, 1997, 1999). The detection limit for cocaine was $100 \mathrm{fmol}$, which corresponded to $0.2 \mu \mathrm{M}$. Concentrations of cocaine in the dialysate were determined by comparing with known concentrations of standards.

\section{Histology}

Animals were killed by decapitation under pentobarbital anesthesia at the end of the microdialysis session and the brains were removed and frozen at $-80^{\circ} \mathrm{C}$. Frozen brains were warmed to $-20^{\circ} \mathrm{C}$ and sections $(20 \mu \mathrm{m})$ were taken at the cannula track and placement verified with microscopy following fixation and staining (Klüver and Barrera, 1953).

\section{Data Analysis}

For isobolographic analysis, the ascending limb of the doseeffect curve was used since the descending limb likely results from multiple effects of the drug (Tallarida et al, 1997). Since there were differences in the maxima of the dose-effect curves for cocaine and heroin, the dose of drug that resulted in the self-administration of 15 infusions/ hourly component was determined for cocaine and heroin alone or in combination ( $\left.A_{15 \text { infusions }}\right)$ using a nonlinear curve fit of the ascending limb of the dose-effect curve for each individual animal using Prism software (GraphPad, San Diego, CA). Isobolograms were generated from the $A_{15}$ injusions values for cocaine and heroin alone and in combination. The interaction between cocaine and heroin was evaluated for synergism according to previously published methods by calculating the theoretical additive dose combination that would result in 15 infusions $\left(Z_{\text {add }}\right)$ and comparing this value to the experimental value $\left(Z_{\text {mix }}\right)$ as described previously (Tallarida et al, 1997).

Microdialysis data were analyzed using a two-way ANOVA with drug (cocaine, heroin, or cocaine/heroin combinations) and dose component serving as the independent variables and either $\%$ of baseline or dialysate concentrations of $[\mathrm{DA}]_{\mathrm{e}}$ as the dependent measure followed by post hoc analysis of differences between means using Bonferroni $t$-tests for multiple comparisons. Cocaine concentrations were analyzed by two-way ANOVA with drug (cocaine/heroin combination or cocaine) and session dose component serving as the independent variables and $[\mathrm{Coc}]_{\mathrm{e}}$ as the dependent measure, followed by post hoc analysis of differences between means using Bonferroni $t$-tests for multiple comparisons. The ratios of $[\mathrm{DA}]_{\mathrm{e}} /$ cocaine concentration were analyzed by one-way ANOVA.

\section{RESULTS}

\section{Isobolographic Analysis of Self-Administration of Cocaine, Heroin, and Cocaine/Heroin Combinations}

The six rats in the isobolographic analysis experiment required 100-150 sessions to complete the experiment. Cocaine, heroin, and their combination all maintained selfadministration with an inverted U-shaped dose-effect curve (Figure 1). The addition of heroin to cocaine shifted the dose-effect curve for self-administration to the left relative to either drug alone. The maxima in the dose-effect curves were not significantly different between cocaine and cocaine/heroin combinations, which were both substantially greater than the maximum in the heroin dose-effect curve. Since the maxima of the cocaine and heroin dose-effect curves were different, $A_{50}$ values for statistical evaluation of the interaction between cocaine and heroin would not provide accurate data (Tallarida et al, 1997), the doses of cocaine, heroin, or the combination that resulted in delivery

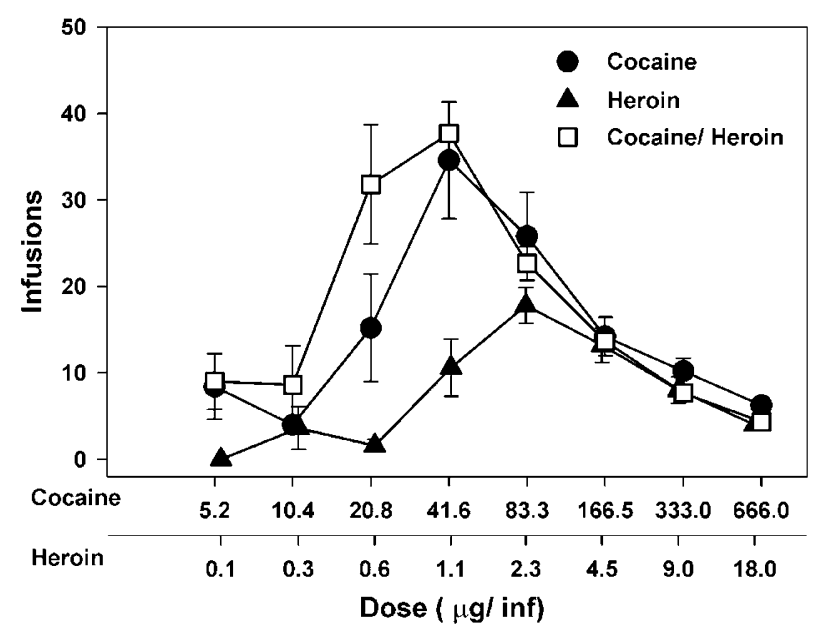

Figure I Dose-effect curves for cocaine, heroin, and cocaine/heroin combinations for six rats using a within session dose-intake procedure. The dose-effect curves were obtained by exposing each rat to three doses of drug in each session. The concentration of each drug was altered until complete dose-intake functions for each drug or combination were determined. 
of 15 infusions were calculated from the nonlinear curve fit of the ascending limb of the dose-effect curve (Figure 2). These values were calculated for each individual animal and used to calculate the theoretical additive dose of the combination $\left(Z_{\text {add }}\right)$ from the dose-effect curve of each drug alone and the actual additive dose $\left(Z_{\text {mix }}\right)$ determined from the combination dose-effect curve. The $Z_{\text {add }}, Z_{\text {mix }}$, and their respective SEM values were converted to the logarithmic values for statistical comparisons as described by Tallarida et al (1997) (Table 1). Students $t$-test indicated that $\log Z_{\text {mix }}$ was not significantly different from $\log Z_{\text {add }}$ at the $p<0.05$ level, consistent with an additive behavioral effect.

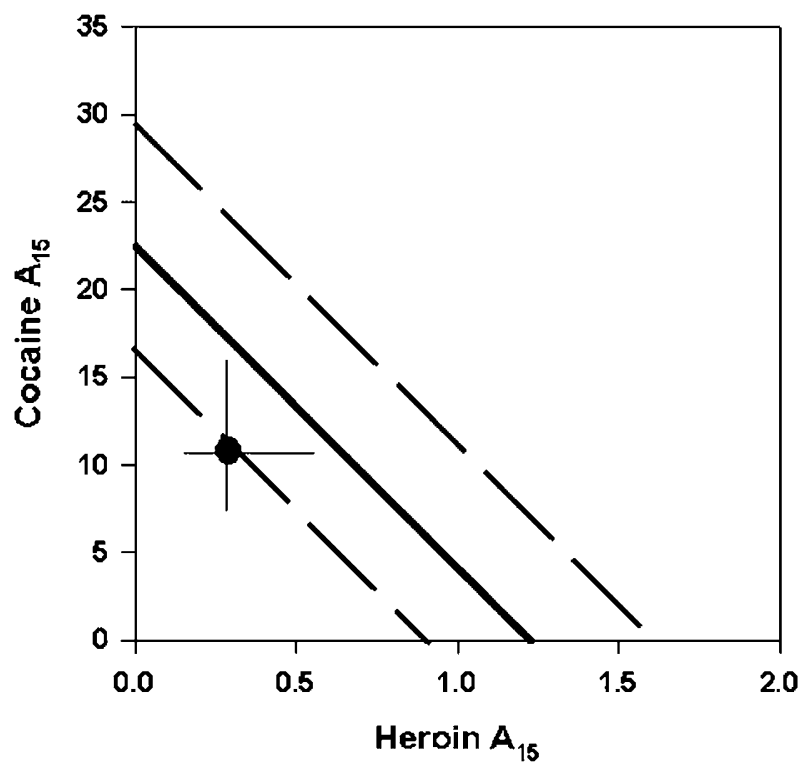

Figure 2 Isobolographic analysis of the self-administration of cocaine and heroin alone or in combination. The dose producing self-administration of 15 infusions on the ascending limb of the dose-effect curves $\left(A_{15}\right.$ infusion (95\% confidence limit)) for each drug presented alone are plotted on the $X$ - (heroin) or $Y$ - (cocaine) axis. The $A_{15}$ infusion (95\% confidence limit) is plotted for the combination of cocaine/heroin in the middle portion of the graph

Table I Behavioral Interaction of Cocaine and Heroin

\begin{tabular}{lccc}
\hline & Cocaine $(\boldsymbol{\mu g} / \mathbf{i n f})$ & Heroin $(\boldsymbol{\mu g} / \mathbf{i n f})$ & Interaction \\
\hline Alone & $22.3(17.1-29.3)$ & $1.21(0.9-1.6)$ & \\
Combined & $10.8(7.1-16.1)$ & $0.29(0.2-0.6)$ & \\
$Z_{\text {add }}$ & & & $15.3 \pm 2.0$ \\
$\log Z_{\text {add }}$ & & & $1.18 \pm 0.06$ \\
$Z_{\text {mix }}$ & & & $11.09 \pm 2.3$ \\
$\log Z_{\text {mix }}$ & & & $1.04 \pm 0.09$ \\
\hline
\end{tabular}

The values shown are the doses $(95 \% \mathrm{CL})$ resulting in 15 infusions being delivered on the ascending limb of the dose-effect curve, as described in Materials and methods. The theoretical additive dose of the combination $\left(Z_{\text {add }}\right)$ or the actual combined dose determined experimentally $\left(Z_{\text {mix }}\right)$ with the corresponding SEM values were calculated according to the methods described by Tallarida et al (1997). Statistical comparison of $Z_{\text {mix }}$ and $Z_{\text {add }}$ was performed using the $t$-statistic as described by Tallarida et al (1997), and these values were not significantly different $(p>0.05)$.
Self-Administration of Cocaine, Heroin, and Cocaine/Heroin Combinations in the Microdialysis Experiment

The 17 rats in the microdialysis experiment required $57.2 \pm 3.6$ (sessions \pm SEM) to complete the experiment. Cocaine maintained drug intake in a dose-dependent manner (Figure 3). Responding was more variable at the $41.6 \mu \mathrm{g}$ dose, which was at the threshold for self-administration under these training conditions $(31.0 \pm 11.2$ infusions). The variability was the result of the rats either not taking this dose or taking a high level of infusions. Heroin intake at threshold doses was not dose dependent, with greater variability at the lowest dose $(1.1 \mu \mathrm{g} /$ infusion $)$ for similar reasons as those outlined above for the lowest cocaine dose. The intake of cocaine/heroin combinations was dose dependent at the two highest doses (cocaine/ heroin - 166.5/4.5 and 83.3/2.3 $\mu \mathrm{g}$ ), with similar intake to cocaine at the highest dose and to heroin at the two lowest doses.

\section{Effects of Microdialysis on Drug Intake}

The microdialysis procedure did not alter baseline drug intake. The intakes of all three doses of cocaine, heroin, and cocaine/heroin combinations were not different on the day of microdialysis from the day before (Figure 4): cocaine $166.5 \mu \mathrm{g}$ dose $(\mathrm{F}(1,8)=0.144, p=0.714) ; 83.3 \mu \mathrm{g}$ dose $(\mathrm{F}(1,8)=1.016, \quad p=0.343) ;$ and $41.6 \mu \mathrm{g}$ dose $(\mathrm{F}(1,8)=$ $0.201, p=0.666)$; heroin $4.5 \mu \mathrm{g}$ dose $(\mathrm{F}(1,10)=0.923$, $p=0.359) ; 2.3 \mu \mathrm{g}$ dose $(\mathrm{F}(1,10)=0.307, p=0.592)$; and $1.1 \mu \mathrm{g}$ dose $(\mathrm{F}(1,10)=3.299, p=0.099)$; and cocaine/heroin combinations $166.5 \mu \mathrm{g} / 4.5 \mu \mathrm{g}$ dose $(\mathrm{F}(1,10)=0.471, p=0.508)$; $83.3 \mu \mathrm{g} / 2.3 \mu \mathrm{g}$ dose $(\mathrm{F}(1,10)=0.083, p=0.779)$; and $41.6 \mu \mathrm{g} /$ $1.1 \mu \mathrm{g}$ dose $(\mathrm{F}(1,10)=1.068, p=0.326)$.

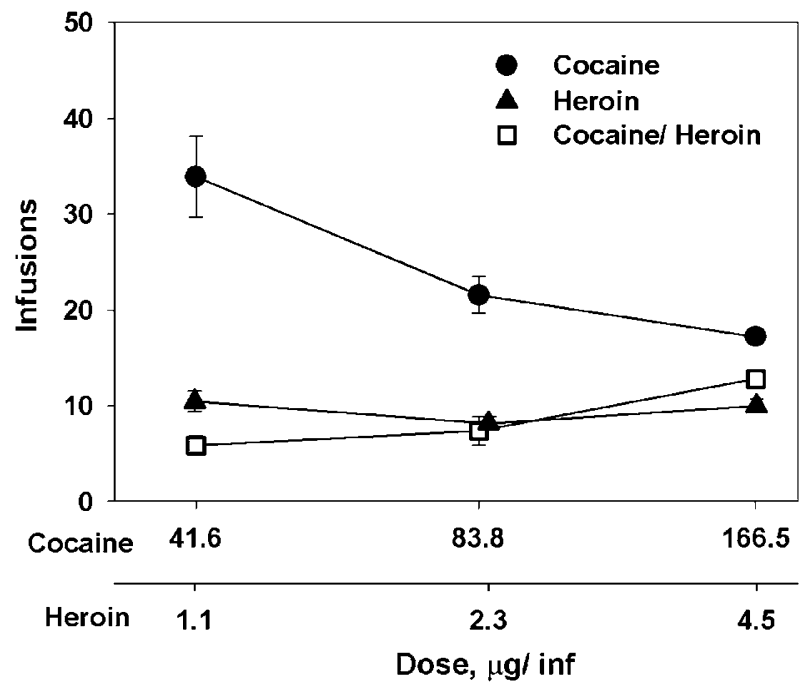

Figure 3 Dose-intake relationship for the rats in the microdialysis experiments. Microdialysates from the NAc were collected during the selfadministration of cocaine $(N=5)$, heroin $(N=6)$, and cocaine/heroin combinations $(N=6)$. The dose-intake values were obtained by exposing each rat to three doses of drug during each session. 


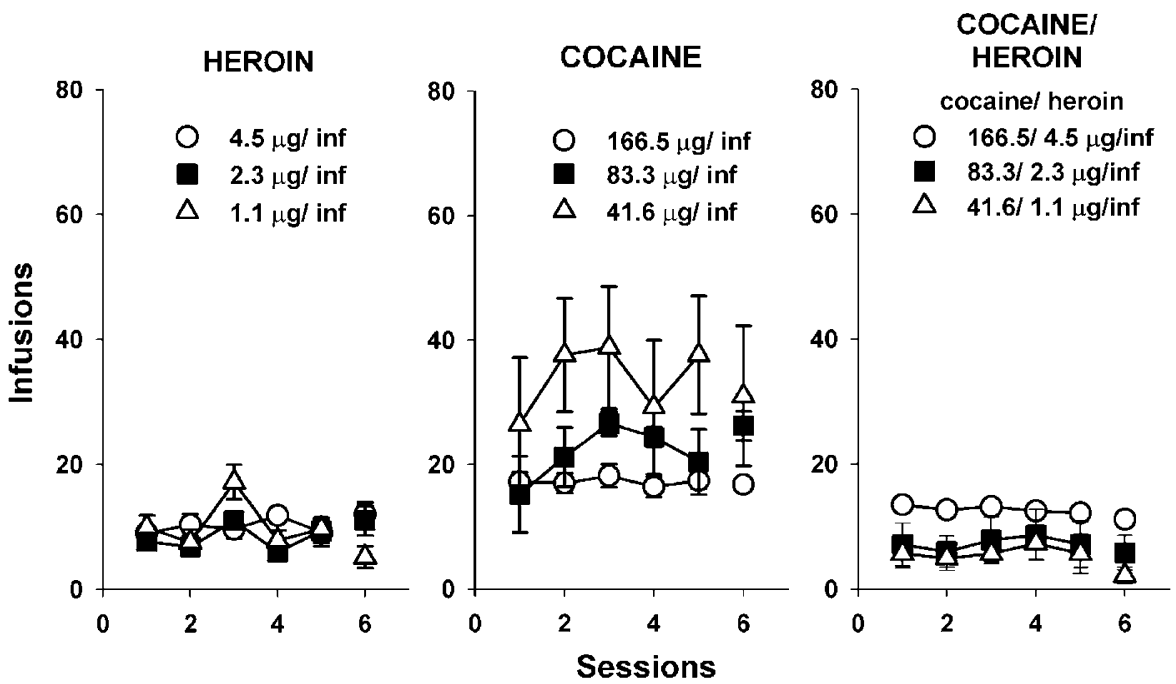

Figure 4 Intake of three doses of heroin, cocaine, and cocaine/heroin combinations five sessions prior to and during the microdialysis session. Intake during the microdialysis session was not different at any of the three doses of the three drug conditions from the 5-day baseline. Points are means and error bars standard deviations for $N=6$ at each point for heroin and cocaine/heroin combinations and $N=5$ for cocaine. When no error bar is shown, error is less than the size of the data point.

\section{Dopamine Concentrations in Microdialysates of the NAc during Self-Administration}

The self-administration of cocaine, heroin, and cocaine/ heroin combinations resulted in significantly different DA levels in NAc microdialysates (Figures 5-7) even though basal levels prior to the self-administration session were not different (cocaine group- $12.0 \pm 1.6 \mathrm{nM}$ of DA; heroin group $-9.5 \pm 2.7 \mathrm{nM}$ of DA; and cocaine/heroin combination group $-8.7 \pm 1.3 \mathrm{nM}$ of DA - values are means \pm SEM). The overall effects of the self-administration of the three different drugs on $[\mathrm{DA}]_{\mathrm{e}}$ were different between each drug $(\mathrm{F}(2,14)=16.22, p<0.001)$ and drug dose $(\mathrm{F}(3,42)=71.24$, $p<0.001)$. Moreover, a significant interaction was observed between the drug and dose $(\mathrm{F}(6,42)=16.78, p<0.001)$. Although dialysate concentrations of DA include variations resulting from probe recovery which are not consistent from probe to probe, the same statistics were completed using those data, which resulted in almost identical results. The overall effects of the self-administration of the three drugs on the levels of DA in the microdialysates were different between each drug $(\mathrm{F}(2,14)=7.08, p<0.01)$ and drug dose $(\mathrm{F}(3,56)=55.27, p<0.001)$. A significant interaction was also seen between drug and dose $(\mathrm{F}(8,56)=16.65, \quad p<0.001)$. Post hoc analysis of the difference between means assessed with the Bonferroni $t$ tests for multiple pairwise comparisons of the percent change in $[D A]_{e}$ from baseline found that heroin selfadministration did not result in significant changes in NAC $[D A]_{\mathrm{e}}$ from baseline at any of the three doses selfadministered (Figure 6). In contrast, the effects of cocaine $(p<0.001)$ and cocaine/heroin combination $(p<0.001)$ on $\mathrm{NAc}[\mathrm{DA}]_{\mathrm{e}}$ differed significantly from heroin, but not from each other. Cocaine resulted in significant increases in $[D A]_{e}$ at all three doses compared to heroin (high$-p<0.001$; mid $-p<0.001$; and low $-p<0.008$ ), as did the higher two doses of cocaine/heroin combinations (high $-p<0.001$; mid $-p=0.021$ ).

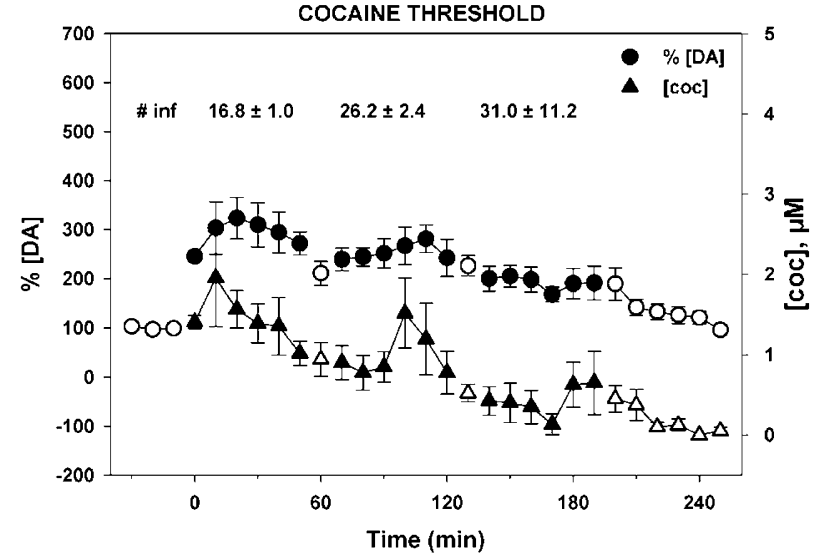

Figure 5 NAc extracellular fluid levels of dopamine (circles) and cocaine (triangles) during self-administration of threshold levels of cocaine. Rats $(N=5)$ were trained to self-administer threshold doses of cocaine (I 66.5, 83.3 , and $41.6 \mu \mathrm{g} /$ infusion) in descending order and the levels of dopamine and cocaine measured in 10-min microdialysate samples from the nucleus accumbens. DA levels are expressed as a percentage of baseline and cocaine as micromoles in samples collected at 10-min intervals (error bars represent \pm SEMs). Open symbols represent data for pre- and post-session and TO periods between doses. The infusions taken per component (mean \pm SEM) are shown at the top of the figure. The extracellular fluid levels of dopamine were elevated at threshold doses of cocaine.

\section{Cocaine Concentrations in Microdialysates of the NAc}

The amount of cocaine detected in microdialysates during the self-administration sessions was lower during the intake of the cocaine/heroin combination compared to the selfadministration of cocaine alone $(\mathrm{F}(1,8)=17.99, p=0.003)$. Drug dose also resulted in differences in $[\mathrm{Coc}]_{\mathrm{e}}$ $(\mathrm{F}(3,24)=37.34, p=0.001)$, with a significant interaction between drug and dose $(\mathrm{F}(3,24)=4.54, p=0.012)$. [Coc $]_{\mathrm{e}}$ was elevated in the cocaine group at the highest two doses (high $-p=0.001$; mid $-p=0.001$ ), but not at the lower dose compared to pre-session baseline. 


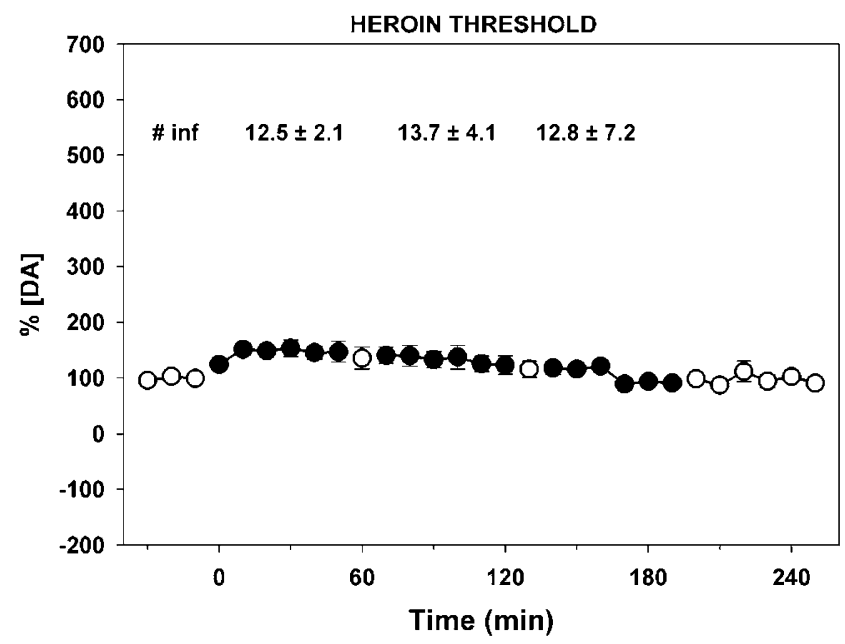

Figure 6 NAc extracellular fluid levels of dopamine (circles) during selfadministration of threshold levels of heroin. Rats $(N=6)$ were trained to self-administer threshold doses of heroin (4.5, 2.3, and I.I $\mu \mathrm{g} /$ infusion) in descending order and the levels of dopamine measured in $10 \mathrm{~min}$ microdialysates of the NAC. DA levels are expressed as a percentage of baseline and cocaine as micromoles in samples collected at 10 min intervals (error bars represent \pm SEMs). Open symbols represent data for pre- and post-session and TO periods between doses. The infusions taken per component (mean \pm SEM) are shown at the top of the figure. The extracellular fluid levels of dopamine were marginally elevated at threshold self-administration doses of heroin.

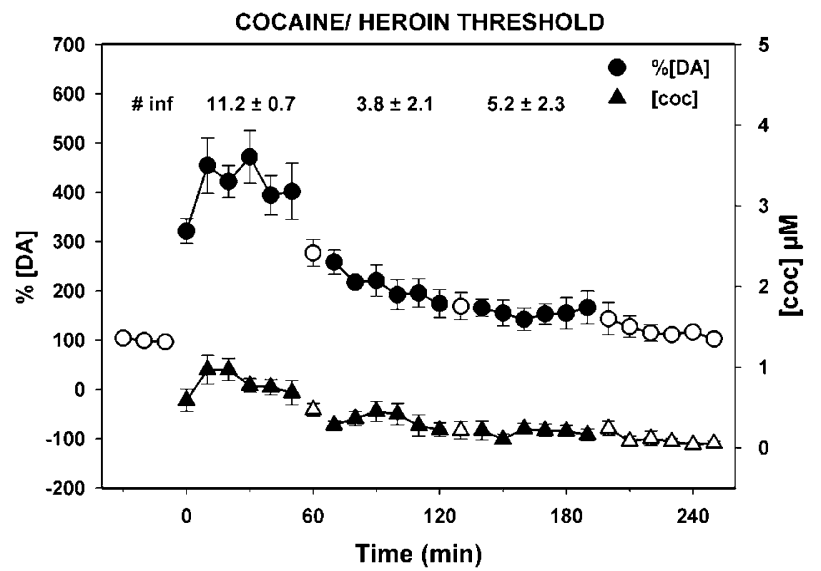

Figure 7 NAc extracellular fluid levels of dopamine (circles) and cocaine/heroin combination (triangles) during self-administration of threshold levels of cocaine. Rats $(N=6)$ were trained to self-administer threshold doses of cocaine/heroin combination (cocaine/heroin - 166.5/4.5, 83.3/2.3 and $41.6 / 1.1 \mu \mathrm{g}$ /infusion) in descending order and the levels of dopamine and cocaine measured in 10-min microdialysates of the NAC. DA levels are expressed as a percentage of baseline and cocaine as micromoles in samples collected at I0-min intervals (error bars represent \pm SEMs). Open symbols represent data for pre- and post-session and TO periods between doses. The infusions taken per component (mean \pm SEM) are shown at the top of the figure. The extracellular fluid levels of dopamine were elevated at threshold doses of cocaine/heroin combination.

\section{Ratio of $[\mathrm{DA}]_{\mathrm{e}} /$ Cocaine Concentrations in Microdialysates of the NAc}

The enhancement of the effects of cocaine by heroin on dopaminergic tone demonstrated by extracellular fluid levels of dopamine was even more pronounced when

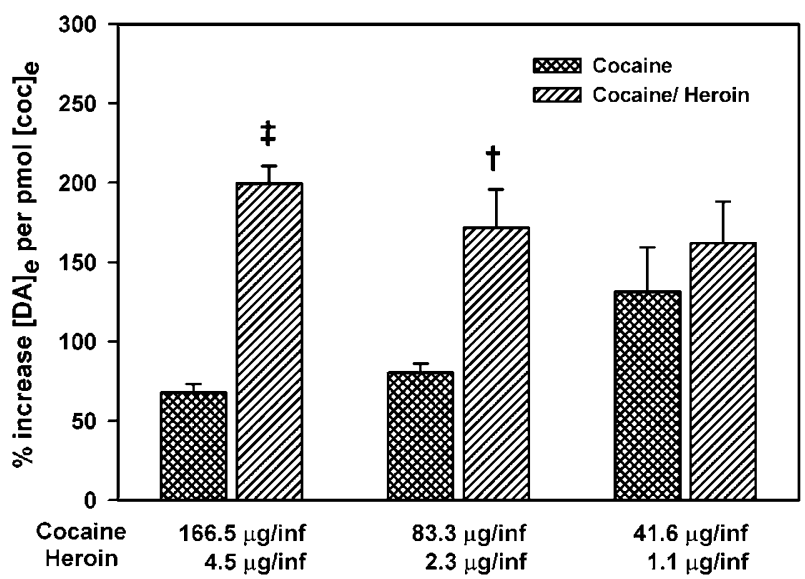

Figure 8 The percent increases in NAc extracellular dopamine above baseline per unit of cocaine in cocaine and cocaine/heroin combination selfadministering rats. The drug intake between cocaine and cocaine/heroin combination self-administering rats was very different (Figures I and 3) as were the resulting cocaine levels in the microdialysates, yet the levels of dopamine were similar to the cocaine group. The levels of dopamine were corrected for those differences by calculating the percent dopamine increase per unit of cocaine in the microdialysate. A one-way ANOVA was used to analyze differences between the ratios of $[D A]_{e} /$ cocaine concentration. Significant differences were: ${ }^{\ddagger} p<0.000$ I; ${ }^{\dagger} p<0.00$ I. The potentiation by heroin of the effects of cocaine on extracellular dopamine is even more evident.

$[D A]_{e}$ was normalized to the concentration of cocaine in the microdialysates (Figure 8). An increased effect of the cocaine/heroin combination relative to cocaine was seen at the high and mid doses in the self-administration session when the ratios of $[\mathrm{DA}]_{\mathrm{e}}$ to cocaine concentration were compared between microdialysates collected during the self-administration sessions. The ratios were calculated using the data for all of the microdialysates from each animal. The percent change from baseline for all six microdialysates for each animal during each of the three different dose components was used (36 points per animal). These ratios for the high and mid doses were significantly different: high dose $(F(1,10)=113.71, p<0.0001)$; mid dose $(\mathrm{F}(1,10)=13.55, p=0.004)$; low dose not different. Again almost identical results were obtained when the concentrations of DA in the microdialysates were used instead of the percent of baseline. These ratios for the high and mid doses were significantly different: high dose $(\mathrm{F}(1,10)=42.56$, $p<0.001)$; mid dose $(\mathrm{F}(1,10)=13.02, p<0.005)$; low dose not different.

\section{Histology}

The guide cannula for the microdialysis probes terminated at the dorsal surface of the NAc and microdialysates were collected at the border of the shell and core (Figure 9). Half of the active portion of most microdialysis probes was within the core and the other half within the shell region of the NAc.

\section{DISCUSSION}

The isobolographic analysis (Tallarida et al, 1997) of the self-administration of cocaine, heroin, and cocaine/heroin 

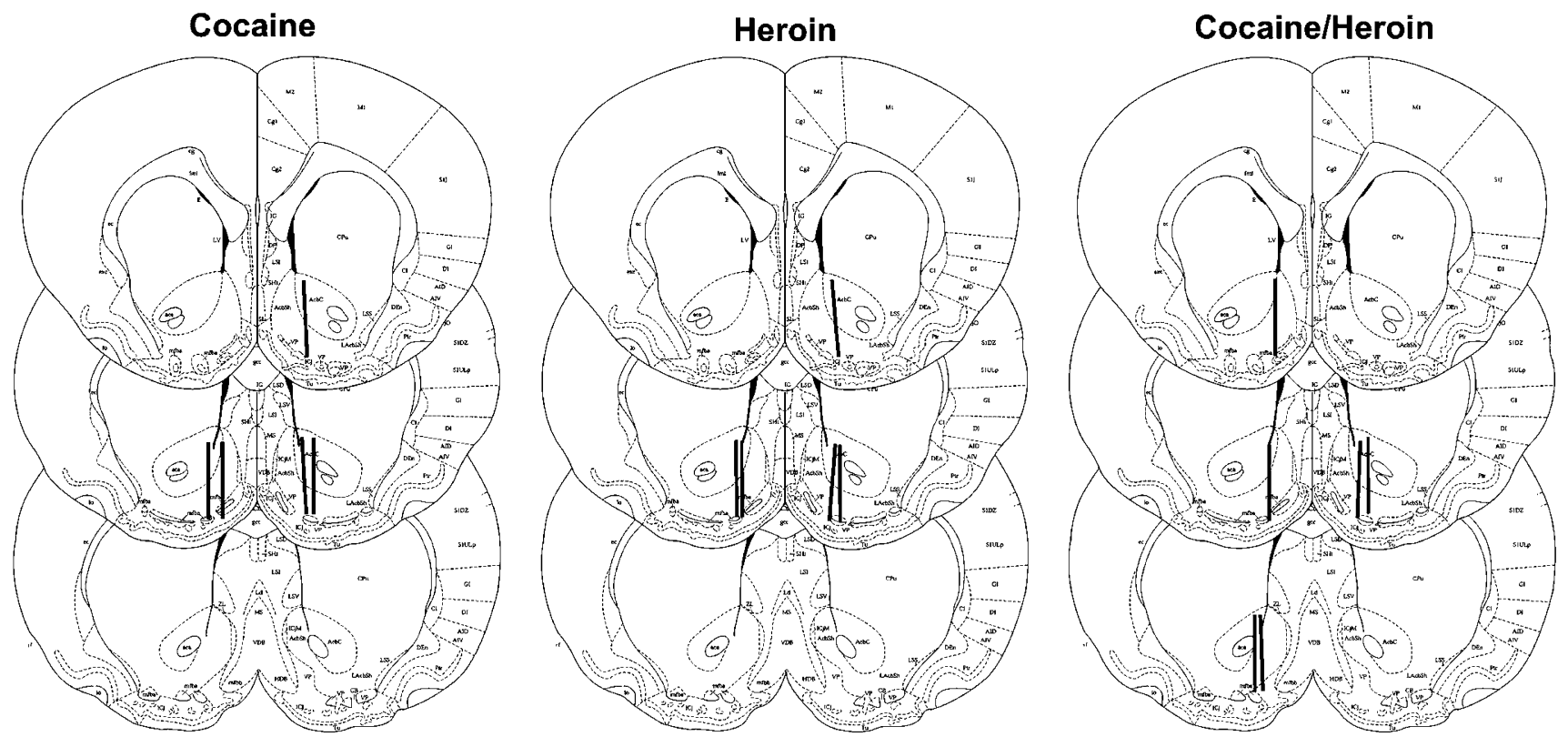

Figure 9 Location of the microdialysis probes in the NAc of cocaine, heroin, and cocaine/heroin combination self-administering rats. The loci for the microdialysis probes are indicated by the dark lines in the diagrams of the brain sections.

combinations showed that responding maintained by the combination was consistent with an additive effect. In contrast, similar doses of cocaine and cocaine/heroin combinations significantly increased $\mathrm{NAc}[\mathrm{DA}]_{\mathrm{e}}$ while heroin did not. These low doses of heroin potentiated the effects of cocaine on $[D A]_{e}$ in a manner similar to that previously reported for self-administration of low doses of cocaine and heroin with a progressive ratio schedule (Duvauchelle et al, 1998) and for doses on the descending limb of the dose-intake relationship (Hemby et al, 1999). The disconnect between the effects of the combination on $\mathrm{NAc}[\mathrm{DA}]_{\mathrm{e}}$ (supra-additive) and the effects upon reinforcing efficacy (additive) suggest that NAc $[D A]_{e}$ may not be a direct measure of reinforcing efficacy.

\section{Additive Reinforcing Effects of Cocaine and Heroin}

The isobolographic analysis showed an additive effect of combining cocaine and heroin in the injectate. Doses of cocaine below threshold were self-administered when small quantities of heroin were added, which is consistent with previously reported findings and with an additive effect (Duvauchelle et al, 1998). These investigators demonstrated that break points obtained with cocaine/heroin combination were greater than individual low doses of cocaine and heroin which had break points identical to those for the vehicle. However, the isobolographic analysis of the selfadministration of the cocaine/heroin combinations reported here using doses on the ascending limb of the dose intake relationship demonstrated an additive relationship. These data suggest that the potentiation of the effects of cocaine on $[D A]_{e}$ in the NAc by heroin had no behavioral consequences on the rate of drug intake under an FR2 schedule. In contrast, progressive ratio schedules of selfadministration found the combination of cocaine and high doses of heroin to result in higher break points than cocaine alone (Ranaldi and Munn, 1998). However, this was not found in another similar study where lower doses of heroin were employed (Ward et al, 2005).

\section{The Potentiation of Cocaine Effects on NAc $[D A]_{e}$ by Heroin}

Doses of cocaine/heroin combinations on the ascending limb of the dose-intake relationship significantly increased $\mathrm{NAc}[\mathrm{DA}]_{\mathrm{e}}$, while heroin did not. Although the combination of heroin and cocaine decreased intake compared to cocaine alone, NAc $[\mathrm{DA}]_{\mathrm{e}}$ were higher than cocaine alone in the first dose component and similar in the second and third dose components (Figures 5 and 7). Interestingly, the amount of heroin self-administered when combined with cocaine was the same as the heroin alone at the highest dose combination, but 72.2 and $59.4 \%$ at the lower two doses, respectively (Figures 6 and 7). It is possible that the effects of the second and third dose components of NAc $[\mathrm{DA}]_{\mathrm{e}}$ may be subject to carry over effects from the first and second components. However, this would not distract from the significance of the overall findings since the greatest potentiation of $[D A]_{e}$ were actually seen during the first component (Figures 5, 7 and 8). In addition, these were selfadministered doses in all components which may not be as subject to carryover effects since the individual rats are focusing on internal cues related to the desirability of responding for drug infusions. It is believed that brain levels of the drug are critical to the subjective effects that lead to the seeking of an additional infusion.

When $[\mathrm{DA}]_{\mathrm{e}}$ were normalized for $[\mathrm{Coc}]_{e}$ in each microdialysate, the synergistic effects of cocaine/heroin combinations on NAc $[\mathrm{DA}]_{e}$ become more evident (Figure 8 ). The effects of cocaine upon NAc $[\mathrm{DA}]_{\mathrm{e}}$ were 
enhanced over $216 \%$ in the first, $113 \%$ in the second, and $33 \%$ in the third dose components by heroin. Therefore, even at low doses, heroin enhances the effects of cocaine on NAc $[D A]_{e}$ similar to effects previously seen for the descending limb of the dose-intake relationship (Hemby et al, 1999). However, these interactions may be specific to the drug mixture ratio chosen here (37: 1 cocaine to heroin) and not seen at other mixture ratios.

Although models have been proposed (Pettit and Justice, 1991), the relationships between low doses of self-administered cocaine and $[D A]_{e}$ have not been previously evaluated for doses near the threshold for self-administration. It was possible that the increased $[\mathrm{DA}]_{\mathrm{e}}$ previously seen for doses on the descending limb of the dose-intake relationship would not be observed at lower doses of self-administered cocaine. In addition, the self-administration of heroin at doses on the descending limb that did not show an increase in NAc $[D A]_{e}$ could result from inhibitory effects that mask or overshadow low-dose stimulatory effects. If this were true, then it could explain the absence of elevated levels previously reported from this laboratory (Hemby et al, 1995, 1999), which would not be expected to be a factor at doses on the ascending limb. Low-dose stimulatory and high-dose inhibitory effects of opiates have been reported for brain stimulation reward thresholds (Kornetsky and Esposito, 1979). However, the present data found that threshold doses of self-administered heroin did not elevate $\mathrm{NAc}[\mathrm{DA}]_{\mathrm{e}}$. In addition, the results of the microdialysis data at these low doses complement previously published studies (Hemby et al, 1995), indicating that cocaine self-administration induces significant elevations in NAc $[\mathrm{DA}]_{\mathrm{e}}$ across a broad range of doses (41.6-666 $\mu \mathrm{g} / \mathrm{infusion})$. Moreover, the potentiation by heroin of cocaine's effect upon NAc $[D A]_{e}$ at low doses could be part of a potential mechanism for the enhanced reinforcing efficacy previously reported in animals (Ranaldi and Munn, 1998) and humans (Ellinwood et al, 1976; Wesson and Smith, 1977; Kosten et al, 1986, 1987; Rosen and Kosten, 1991; Tutton and Crayton, 1993). The isobolographic analysis used here does not support a super-additive effect of the dose combination even though effects on NAc [DA $]_{\mathrm{e}}$ were found to be super-additive.

\section{Potential Mechanisms}

Although the mechanism of this neurochemical potentiation is not currently known, several lines of evidence suggest interactions between opiates and stimulants (Stinus et al, 1992; Wood, 1983). Opioid receptors are located on a subset of dopaminergic neurons within the mesolimbicmesocortical systems (Goodman et al, 1988; Mansour et al, 1988; Sharif and Hughes, 1989; Garzón and Pickel, 2001), while the majority of $\mu$-opioid receptors in the VTA are located on GABAergic interneurons (Garzon and Pickel, 2001). Systemic administration of opioid antagonists decreased stimulant-induced locomotor activity (Adams and Holtzman, 1991; Jones and Holtzman, 1992; Jones et al, 1993) and increases in NAc $[D A]_{\mathrm{e}}$ (Hooks et al, 1992). Furthermore, perturbation of opioid receptors modulated cocaine self-administration. Pretreatment with naltrexone decreased intravenous cocaine intake (Carroll et al, 1986; Corrigall and Coen, 1991) and suppressed acquisition of self-administration in rodents (Ramsey and van Ree, 1991).
In addition, binge cocaine administration increased preproenkephalin and preprodynorphin mRNA in the striatum (Daunais et al, 1993, 1995; Spangler et al, 1996; Hurd et al, 1992) and cocaine administration increased $\mu$-opioid receptor mRNA in the NAc (Azaryan et al, 1996). Opioid receptors may be involved in cocaine craving since $\mu$-opioid receptor binding measured with positron emission tomography in the brains of cocaine addicts after 1-4 days of withdrawal was increased and positively correlated with the severity of cocaine craving (Zubieta et al, 1996).

\section{Brain Sites of Potentiation}

The sites at which heroin could enhance the actions of DA include the ventral tegmental area (VTA), NAc, and ventral pallidum (VP). The VTA has relatively few $\mu$ - or $\delta$-opioid receptors; however, opioid agonists injected into this region produce profound effects on locomotor activity and increase NAc $[D A]_{e}$, suggesting that this relatively small population of receptors may have an important role in the mediation of NAc function (Kalivas, 1985; Joyce and Iversen, 1979; Devine et al, 1993). It is possible that the potentiation of $\mathrm{NAc}[\mathrm{DA}]_{\mathrm{e}}$ seen here results from the actions of heroin metabolites upon opioid receptors on DA cell bodies in the VTA. GABA projections from the VTA to the NAc shell contain presynaptic $\mu$-opioid receptors (Svingos et al, 1997). In addition, medium spiny neurons that project to the VTA from the NAc contain $\mu$-opioid receptors, suggesting that heroin could modulate these inhibitory fibers directly at the level of the NAc (Zahm et al, 1985). Activation of these receptors would hyperpolarize the GABAergic synapse, resulting in disinhibition of DA release in the NAc. This is supported by data showing injections of naltrexone into the VTA to attenuate intravenous cocaine self-administration (Ramsey et al, 1999), while injection of DAMGO, a $\mu$ receptor agonist, shifted the dose-intake relationship for self-administered cocaine to the left (Corrigall et al, 1999). In addition, the administration of the $\mathrm{D}_{1}$ or $\mu$-opioid receptor antagonist directly into the NAc decreased break points for the self-administration of cocaine/heroin combinations in rats (Cornish et al, 2005). These data clearly support the involvement of NAc, and VTA in the processes underlying the self-administration of cocaine and cocaine/heroin combinations.

$\mathrm{Mu}$ opioid receptors are found in dense patches in the NAc, with the greatest density of receptors being in the more rostral and medial aspects (Mansour et al, 1987; Tempel and Zukin, 1987). Delta opioid receptors are also dense in the NAc relative to other structures, but are not localized in patches and are less abundant than $\mu$-opioid receptors (Mansour et al, 1987). GABAergic mechanisms have a prominent inhibitory role in the fast synaptic transmission in the NAc (Chang and Kitai, 1986; Pennartz and Kitai, 1991). GABA release in the NAc is thought to originate primarily from inhibitory interneurons intrinsic to this structure although there is evidence that the VTA and VP send GABA releasing neurons to the NAc (Van Bockstaele and Pickel, 1995; Groenewegen et al, 1993). GABA releasing medium-spiny neurons not only form the principal projections from the NAc, but also branch locally in a dense network overlapping their own dendrites (Shi and Rayport, 1994) resulting in autoregulation (Pickel et al, 
1988; Meredith and Wouterlood, 1994). Facilitation of GABA-release in the NAc attenuates DA release (Tanganelli et al, 1994), and therefore it is likely that inhibition of GABA release locally in the NAc by heroin would potentiate the effect of self-administered cocaine on NAc $[D A]_{e}$. The GABA projections to the VTA from the VP also contain $\mu$ opioid receptors that could impact VTA dopaminergic output to both the VP and NAc, as inhibition of GABAergic tone within the VTA increases $[\mathrm{DA}]_{\mathrm{e}}$ in the NAc (Ikemoto et al, 1997). Therefore, another possible mechanism through which heroin could potentiate the increase in $\mathrm{NAc}[\mathrm{DA}]_{e}$ could be through a decrease in the inhibitory feedback mechanisms that arise in the projections from the NAc to the VP and VTA.

\section{Conclusion}

The reinforcing effects of low doses of cocaine are enhanced in an additive manner by the addition of low-dose heroin to the injectate. Low doses of cocaine and cocaine/heroin combinations significantly increased $\mathrm{NAc}[\mathrm{DA}]_{\mathrm{e}}$, while heroin had no effect. Although the combination of heroin and cocaine decreased intake compared to cocaine alone, $\mathrm{NAc}[\mathrm{DA}]_{\mathrm{e}}$ were increased in a supra-additive manner when $\mathrm{NAc}[\mathrm{DA}]_{\mathrm{e}}$ was normalized to the $[\mathrm{Coc}]_{\mathrm{e}}$. This demonstrates that NAc $[D A]_{e}$ may not be a direct index of reinforcing efficacy since the reinforcing efficacy of this combination was additive but the effects upon NAc $[D A]_{e}$ were supraadditive. The potentiation of the neurochemical effects of cocaine by heroin is likely through $\mu$ and $\delta$ opiate receptors in the NAc, VP, and/or VTA. These data may also suggest a neurobiological substrate for the larger systemic pharmacological effects of cocaine seen in laboratory studies of addicts when opiates are co-administered (Foltin et al, 1995; Preston et al, 1996) and perhaps for the high percentage of cocaine-positive urines in patients maintained on higher methadone doses, since it is possible that the additive effects of the combination with cocaine result in reinforcing stimuli that are not present with methadone alone (Grabowski et al, 1993; Rhoades et al, 1998).

\section{ACKNOWLEDGEMENTS}

The conduct of this experiment was consistent with the ethical standards outlined in Principles of laboratory animal care (NIH publication No. 80-23, revised 1996). This research was supported by grants from the National Institute on Drug Abuse: DA 12498, DA 06634 and DA00114 (to JES); NS38231 (TJM); and DA 13234 and DA13772 (to SEH).

\section{REFERENCES}

Adams JU, Holtzman SG (1991). Naltrexone-sensitizing effects of centrally administered morphine and opioid peptides. Eur $J$ Pharm 193: 67-73.

Azaryan AV, Clock BJ, Cox BM (1996). Mu opiod receptor mRNA in nucleus accumbens is elevated following dopamine receptor activation. Neurochem Res 21: 1411-1415.

Brown ZW, Amit Z, Weeks JR (1976). Simple flow-thru swivel for infusions into unrestrained animals. Pharmacol Biochem Behav 5: $363-365$.
Brown EE, Finlay JM, Wong JT, Damsma G, Fibiger HC (1991). Behavioral and neurochemical interactions between cocaine and buprenorphine: implications for pharmacotherapy of cocaine abuse. J Pharmacol Exp Ther 256: 119-126.

Carroll ME, Lac ST, Walker MJ, Kragh R, Newman T (1986). Effects of naltrexone on intravenous cocaine self-administration in rats during food satiation and deprivation. J Pharmacol Exp Ther 238: $1-7$.

Chang H, Kitai ST (1986). Intracellular recordings from rat nucleus accumbens neurons in vitro. Brain Res 366: 392-396.

Cornish JL, Lontos JM, Clemons KJ, McGregor IS (2005). Cocaine and heroin ('speedball') self-administration: the involvement of nucleus accumbens dopamine and $\mu$-opiate, but not $\delta$ opiate receptors. Psychopharmacology (published online 29 January 2005).

Corrigall WA, Coen KM (1991). Opiate antagonists reduce cocaine but not nicotine self-administration. Psychopharmacology 104: 167-170.

Corrigall WA, Coen KM, Adamson KL, Chow BLC (1999). The mu opioid agonist DAMGO alters the intravenous self-administration of cocaine in rats: mechanisms in the ventral tegmental area. Psychopharmacology 141: 428-435.

Craddock SG, Rounds-Bryant JL, Flynn PM, Hubbard RL (1997). Characteristics and pretreatment behaviors of clients entering drug abuse treatment: 1969 to 1993. Am J Drug Alc Abuse 23: 43-59.

Daunais JB, Roberts DCS, McGinty JF (1995). Short-term cocaine self-administration alters striatal gene expression. Brain Res Bull 37: 523-527.

Daunais JB, Roberts DCS, McGinty JF (1993). Cocaine selfadministration increases preprodynorphin, but not c-fos, mRNA in rat striatum. Neuro Report 4: 543-546.

Devine DP, Leone P, Pocock D, Wise RA (1993). Differential involvement of ventral tegmental $\mathrm{mu}$, delta and kappa opioid receptors in modulation of basal mesolimbic dopamine release: in vivo microdialysis studies. J Pharmacol Exp Ther 266: 1236-1246.

Di Chiara G, Imperato A (1988). Drugs abused by humans preferentially increase synaptic dopamine concentrations in the mesolimbic system of freely moving rats. Proc Natl Acad Sci USA 85: 5274-5278.

Downey KK, Helmus TC, Schuster CR (2000). Treatment of heroindependent poly drug abusers with contingency management and buprenorphine maintenance. Exp Clin Psychopharmacol 8: 176-184.

Duvauchelle CL, Sapoznik T, Kornetsky C (1998). The synergistic effects of combining cocaine and heroin ('speedball') using a progressive-ratio schedule of drug reinforcement. Pharmacol Biochem Behav 61: 297-302.

Ellinwood Jr EH, Eiberger RD, Kolby MM (1976). Stimulants: interactions with clinically relevant drugs. Am NY Acad Sci NY 281: 393-408.

Foltin RW, Christiansen I, Levin FR, Fischman MW (1995). Effects of single and multiple intravenous cocaine injections in humans maintained on methadone. J Pharmacol Exp Ther 275: 38-47.

Foltin RW, Fischman MW (1992). The cardiovascular and subjective effects of intravenous cocaine and morphine combinations in humans. J Pharmacol Exp Ther 261: 623-632.

Garzón M, Pickel VM (2001). Plasmalemmal $\mu$-opioid receptor distribution mainly in nondopaminergic neurons in the rat ventral tegmental area. Synapse 41: 311-328.

Goodman RR, Adler BA, Patermak GW (1988). Regional distribution of opioid receptors. In: Pasternak CW (ed). The Opiate Receptors. The Humana Press: Clifton, NC. pp 197-228.

Grabowski J, Rhoades HM, Elk R, Schmitz J, Creson D (1993). Methadone dosage, cocaine and opiate abuse. Am J Psychiatry 150: 675 . 
Groenewegen HJ, Berendse HW, Haber SN (1993). Organization of the output of the ventral striatopallidal system in the rat: ventral pallidal efferents. Neuroscience 57: 113-142.

Hemby SE, Co C, Koves TR, Smith JE, Dworkin SI (1997). Differences in extracellular dopamine concentrations in the nucleus accumbens during response-dependent and responseindependent cocaine administration in the rat. Psychopharmacology 133: 7-16.

Hemby SE, Co C, Dworkin SI, Smith JE (1999). Synergistic elevations in nucleus accumbens extracellular dopamine concentrations during 'speedball' self-administration in rats. $J$ Pharmacol Exp Ther 288: 274-280.

Hemby SE, Martin TJ, Co C, Dworkin SI, Smith JE (1995). The effects of intravenous heroin administration on extracellular nucleus accumbens dopamine concentrations as determined by in vivo microdialysis. J Pharmacol Exp Ther 273: 591-598.

Hooks MS, Colvin AC, Juncos JL, Justice Jr JB (1992). Individual differences in basal and cocaine-stimulated extracellular dopamine in the nucleus accumbens using quantitative microdialysis. Brain Res 587: 306-312.

Hurd YL, Brown EE, Finlay JM, Fibiger HC, Gerfen CR (1992). Cocaine self-administration differentially alters mRNA expression of striatal peptides. Brain Res Mol Brain Res 13: 165-170.

Ikemoto S, Kohl RR, McBride WJ (1997). GABA A receptor blockade in the anterior ventral tegmental area increases extracellular levels of dopamine in the nucleus accumbens of rats. J Neurochem 69: 137-143.

Jones DN, Bowen WD, Portoghese PS, Holtzman SG (1993). Deltaopioid receptor antagonists attenuate motor activity induced by amphetamine but not cocaine. Eur J Pharmacol 249: 167-177.

Jones DN, Holtzman SG (1992). Interaction between opioid antagonists and amphetamine: evidence for mediation by central delta opioid receptors. J Pharmacol Exp Ther 262: 638-645.

Joyce EM, Iversen SD (1979). The effect of morphine applied locally to mesencephalic dopamine cell bodies on spontaneous locomotor activity in the rat. Neurosci Lett 14: 207-212.

Kalivas PW (1985). Sensitization to repeated enkephalin administration into the ventral tegmental area of the rat. II. Involvement of the mesolimbic dopamine system. J Pharmacol Exp Ther 235: 544-550.

Klüver H, Barrera EA (1953). A method for the combined staining of cell and fibers in the nervous system. J Neuropath Exp Neurol 12: 400-403.

König JFR, Klippel RA (1967). The Rat Brain. Robert E. Krieger Publishing Co: New York.

Koob GF, Bloom FE (1988). Cellular and molecular mechanisms of drug dependence. Science 242: 715-723.

Kornetsky C, Esposito RU (1979). Euphorigenic drugs: effects on the reward pathways of the brain. Fed Proc 11: 2473-2476.

Kosten TR, Rounsaville BJ, Kleber HD (1987). A 2.5 year follow-up of cocaine use among treated opioid addicts. Arch Gen Psychiat 44: 281-284.

Kosten TR, Rounsaville BJ, Gawan FH, Kleber HD (1986). Cocaine abuse among opioid addicts: demographic and diagnostic factors in treatment. Am J Drug Alcohol Abuse 12: 1-16.

Magura S, Kang SY, Nwakeze PC, Demsky S (1998). Temporal patterns of heroin and cocaine use among methadone patients. Sub Use Misuse 33: 2441-2467.

Mansour A, Kachaturian H, Lewis ME, Akil H, Watson SJ (1987). Autoradiographic differentiation of $\mu, \delta$, and $\kappa$ opioid receptors in the rat forebrain and midbrain. $J$ Neurosci 7: 2445-2464.

Mansour A, Khachaturian H, Lewis ME, Akil H, Watson SJ (1988). Anatomy of CNS opioid receptors. Trends Neurosci 11: 308-314.

Martin TJ, deMontis MG, Kim SA, Sizemore GM, Dworkin SI, Smith JE (1998). Effects of $\beta$-funaltrexamine on dose-effect curves for heroin self-administration in rats: comparison with alteration of $\left[{ }^{3} \mathrm{H}\right] \mathrm{DAMGO}$ binding to rat brain sections. Drug Alcohol Depend 52: 135-147.
Martin TJ, Walker LE, Sizemore GM, Smith JE, Dworkin SI (1996). Within-session determination of dose-response curves for heroin self-administration in rats: comparison with betweensession determination and effects of naltrexone. Drug Alcohol Depend 41: 93-100.

Mattox AJ, Thompson SS, Carroll ME (1997). Smoked heroin and cocaine base (speedball) combinations in rhesus monkeys. Exp Clin Psychopharmacol 5: 113-118.

Mello NK, Negus SS, Lukas SE, Mendelson JH, Sholar JW, Drieze J (1995). A primate model of polydrug abuse: cocaine and heroin combinations. J Pharmacol Exp Ther 274: 1325-1337.

Meredith GE, Wouterlood F (1994). Synaptic organization of the nucleus accumbens (ventral striatum). In: Bernardi G, Carpenter MD, Di Chiara GD, Morelli M, Stanzione P (eds). The Basal Ganglia III: Advances in Behavioral Biology. Plenum Press: New York. pp 167-176.

Negus SS (2005). Interactions between the reinforcing effects of cocaine and heroin in a drug- $v s$-food choice procedure in rhesus monkeys: a dose-addition analysis. Psychopharmacology (published online 5 February 2005).

Pennartz CMA, Kitai ST (1991). Hippocampal inputs to identified neurons in an in vivo slice preparation of the rat nucleus accumbens: evidence for feed-forward inhibition. J Neurosci 11: 2838-2847.

Pettit HO, Justice Jr JB (1989). Dopamine in the nucleus accumbens during cocaine self-administration as studied by in vivo microdialysis. Pharmacol Biochem Behav 34: 899-904.

Pettit HO, Justice Jr JB (1991). Effects of dose on cocaine selfadministration behavior and dopamine levels in the nucleus accumbens. Brain Res 539: 94-102.

Pickel VM, Towle AC, Joh TH, Chan J (1988). Gammaaminobutyric acid in the medial rat nucleus accumbens: ultrastructural localization in neurons receiving monosynaptic input from catecholaminergic afferents. J Comp Neurol 272: $1-14$.

Pickens R, Dougherty J (1972). Reports from Res Labs Dept Psychiat, Univ Minn, No. PR-72-1.

Preston KL, Sullivan JT, Strain EC, Bigelow GE (1996). Enhancement of cocaine's abuse liability in methadone maintenance patients. Psychopharmacology 123: 15-25.

Ramsey NF, Gerrits MA, van Ree JM (1999). Naltrexone affects cocaine self-administration in naïve rats through the ventral tegmental area rather than dopaminergic target regions. Eur Neuropsychopharmacol 9: 93-99.

Ramsey NF, van Ree JM (1991). Intracerebroventricular naltrexone treatment attenuates acquisition of intravenous cocaine selfadministration in rats. Pharmacol Biochem Behav 40: 807-810.

Ranaldi R, Munn E (1998). Polydrug self-administration in rats: cocaine-heroin is more rewarding than cocaine-alone. Neuroreport 9: 2463-2466.

Ranaldi R, Pocock D, Zereik R, Wise RA (1999). Dopamine fluctuations in the nucleus accumbens during maintenance, extinction, and restatement of intravenous D-amphetamine selfadministration. J Neurosci 19: 4102-4109.

Rhoades HM, Creson D, Elk R, Schmitz J, Grabowski J (1998). Retention, HIV risk, and illicit drug use during treatment: methadone doses and visit frequency. Am J Pub Health 88: 34-39.

Rosen MI, Kosten TR (1991). Buprenorphine: beyond methadone? Hosp Comm Psychiatry 42: 347-349.

Rowlett JK, Woolverton WL (1997). Self-administration of cocaine and heroin combinations by rhesus monkeys responding under a progressive-ratio schedule. Psychopharmacology 133: 363-371.

Schütz CG, Vlahov D, Anthony JC, Graham NMH (1994). Comparison of self-reported injection frequencies for past 30 days and 6 months among intravenous drug users. J Clin Epidemiol 47: 191-195. 
Sharif NA, Hughes J (1989). Discrete mapping of brain mu and delta opioid receptors using selective peptides: quantitative autoradiography, species differences and comparison with kappa receptors. Peptides 10: 499-522.

Shi WX, Rayport S (1994). GABA synapses formed in vitro by local axon collaterals of the nucleus accumbens. J Neurosci 14: $4548-4560$.

Spangler R, Zhou Y, Maggos CE, Zlobin A, Ho A, Kreek MJ (1996). Dopamine antagonist and 'binge'cocaine effects on rat opioid and dopamine transporter mRNA. Neuroreport 7: 2196-2200.

Stinus L, Cador M, Le Moal M (1992). Interaction between endogenous opioids and dopamine within the nucleus accumbens (Review). Ann NY Acad Sci 654: 254-273.

Svingos AL, Moriwaki A, Wang JB, Uhl GR, Pickel VM (1997). Mu opioid receptors are localized to extrasynaptic plasma membranes of GABAergic neurons and their targets in the rat nucleus accumbens. J Neurosci 17: 2585-2594.

Tallarida RJ, Kimmel HL, Holtzman SG (1997). Theory and statistics of detecting synergism between two active drugs: cocaine and buprenorphine. Psychopharmacology 133: 378-382.

Tanganelli S, O'Connor WT, Ferraro L, Bianchi C, Beani L, Ungerstedt $U$ et al (1994). Facilitiation of GABA release by neurotensin is associated with a reduction of DA release in rat nucleus accumbens. Neuroscience 60: 649-657.

Tempel A, Zukin RS (1987). Neuroanatomical patterns of $\mu, \delta$ and $\kappa$ opioid receptors of rat brain as determined by quantitative in vitro autoradiography. Proc Natl Acad Sci USA 84: 4308-4312.

Tutton CS, Crayton JW (1993). Current pharmacotherapies for cocaine abuse: a review. J Addict Dis 12: 109-127.

Van Bockstaele EJ, Pickel VM (1995). GABA-containing neurons in the ventral tegmental area project to the nucleus accumbens in the rat. Brain Res 682: 215-221.

Walsh SL, Sullivan JT, Preston KL, Garner JE, Bigelow GE (1996). Effects of naltrexone on response to intravenous cocaine, hydromorphone and their combinations in humans. J Pharmacol Exp Ther 279: 524-538.
Wang NS, Brown VL, Grabowski J, Meisch RA (2001). Reinforcement of orally delivered methadone, cocaine, and methadonecocaine combinations in rhesus monkeys: are the combinations better reinforcers? Psychopharmacology 156: 63-72.

Ward SJ, Morgan D, Roberts DCS (2005). Comparison of the reinforcing effects of cocaine/heroin combinations under progressive ratio and choice schedules in rats. Neuropsychopharmacology 30: 286-295.

Weeks JR (1962). Experimental morphine addiction: method for automatic intravenous injections in unrestrained rats. Science 138: $143-144$.

Weeks JR (1972). Long-term intravenous infusions. In: Myers RD (ed). Methods in Psychobiology 2. Academic Press: New York. pp 155-168.

Wesson DR, Smith DE (1977). Cocaine: its use for central nervous system stimulation including recreational and medical uses. In: Peterson RC, Stillman RC (eds). Cocaine: 1977. National Institute on Drug Abuse Monograph 13. US Government Printing Office: Washington, DC. pp 137-152.

Wise RA, Leone P, Rivest R, Leeb K (1995). Elevations of nucleus accumbens dopamine and DOPAC levels during intravenous heroin self-administration. Synapse 21: 140-148.

Wood PL (1983). Opioid regulation of CNS dopaminergic pathways: a review of methodology, receptor types, regional variations and species differences. Peptides 4: 595-601.

Zahm DS, Zaborsky SL, Alones VE, Heimer L (1985). Evidence for the coexistence of glutamate decarboxylase and Met-enkephalin immunoreactivities in the axon terminals of rat ventral pallidum. Brain Res 325: 317-321.

Zernig G, O’Laughlin IA, Fibiger HC (1997). Nicotine and heroin augment cocaine-induced dopamine overflow in nucleus accumbens. Eur J Pharmacol 337: 1-10.

Zubieta JK, Gorelick DA, Stauffer R, Ravert HT, Dannals RF, Frost JJ (1996). Increased mu opioid receptor binding detected by PET in cocaine-dependent men is associated with cocaine craving. Nat Med 2: 1225-1229. 